\title{
DYNAMIC AND STATIC PATTERNS IN LANGUAGE: INSTRUMENTAL VERBS UNFOLDED
}

\author{
AndRea Graumann \\ University of Bremen \\ graumann@uni-bremen.de
}

\begin{abstract}
Resumen
Our mental capacity to construe a perceived situation in different ways and the distinct modes of construal become evident when comparing various linguistic structures possible for verbalizing one and the same event. These structures can be distinguished according to a range of different features - among them quantities known from physics: state and dynomics. To demonstrate the gradual difference between static and dynamic concepts discernable in language this paper focuses on distinct presentations of a complex form of causatives - namely instrumentals.

After some introductory comments in section one, section two will display the conceptual differences between plain causative constructions and instrumental construals. The third section analyzes different instrumental patterns with regard to the static-dynamic distinction and the conceptual import of these structures. Some concluding words will close the article.
\end{abstract}

\section{INTRODUCTION}

The physical differentiation into static and dynamic quantities is captured in grammatical categories and syntactic structures. The basic linguistic classification mirrors this distinction: nouns, adjectives, gerunds etc. representing static entities and situations and verbs realizing dynamic events.

While states are describcd as having a spatial but no temporal extension, dynamic events are based not only on spatial but as well on temporal extension. The derivational processes which a language user is capable to (e.g. nominalization, de-nominalization etc.) and our ability to construct a perceived scene and its essential components as static or as dynamic hint at the gap between objective time (i.e. the temporal extension during which an event actually happens) and subjective time (i.e. the perception of the temporal extensions).

As Pöppel (1994) has shown subjective time consists of two units: the $30 \mathrm{msec}$ window for the perception of primordial units (objects) and a $3 \mathrm{sec}$ window for the analysis of events, i.e. of Gesalts and structures. Pöppels subjective time can be correlated to what Langacker calls processing time. This notion of time is contrasted to the notion of conceived time, which Langacker describes «as an OBJECT of conceptualization» (Langacker 2002: 79). Our mental ability to accelerate or decelerate perceived events is discernable in the different linguistic structures which are possible to describe one and the same real-world event. 
The objectivist view that language gets its meaning via correspondences to objects and event in reality is thus negated by cognitive scmantics. Cognitive semantics postulates that language does not represent external reality proper but resides on mental structurcs established during the process of conceptualization of extcrnal events.

Linguistic constructions display the different cognitive patterns thus processed and exhibit the conceptual import applied to the distinct components of the pattern. Cognitive semantics has shown that these construal operations discernable in language are based on imaging or schematic systems, which correspond to structuring mechanisms in other cognitive domains such as visual perception or scnsorimotory control.

In his paper «The Relation of Grammar to Cognition» (2000) Leonard Talmy identified four imaging systems implicit in language:

a) «the schematic structuring or geometric delineations in space or time» (Talmy: 47);

b) "the conceptual perspective point from which the entity is cognitively regarded" (ibid: 68)

c) «the distribution of one's attention over the given structure from the given perspective point» (ibid.: 76)

and

d) «force dynamics» (ibid. 41)

While the first three of these imaging systems arc mainly involved in the structuring of space and time in language, the fourth schema is concerned with the interaction between the entities on the referent scene. Depending on the conceptualized situation and on the construal operations one of these schemes usually dominates over the others - yet they never appear alone in language.

Especially causative constructions, which are regarded as sub-concepts of the force dynamics system, comprise all four systems. Analyzing yet another sub-conccpt of the force dynamics scheme I will focus on attentional aspects displayed in different instrumental structures.

\section{The Instrumental Continulum}

Talmy points out that «in most familiar languages [...] the entire portion of [a complex] sequence is gapped ? (Talmy 2000: 272). This observation is applicable to most causative constructions: Prototypical causative constructions directly depict the relation between cause and result and gap the specific means by which this relation is established.

Instrumental construals incorporate these medial scquences and are thus a more specific and more complex sub-form of causative constructions. Compared to causal patterns instrumental construals encompass a further conceptual compound, i.e. represent the instrument used by an agent to act on a patient. In other words: The instrument represents the means whereby something is done and functions as energy-transmitting medium between agent and patient.

Langacker's encrgy chain captures this distinction between causative and instrumental concepts and provides a vivid starting point for the description of the conceptual differences: 


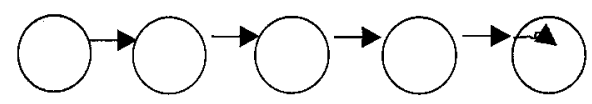

Head (Agens)

Tail (Patiens)

$\left[\right.$ Paul $_{\text {Agens }}$ tötete ${ }_{\text {Cause }}$ den $\left.\mathrm{Käfer}_{\text {Patient }}\right]$

(Paul killed the bug)

Figure 1: Causative Concept

(cf. Langacker 2002: 217)

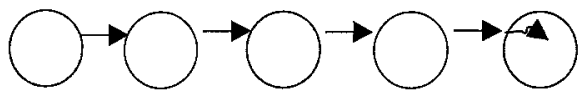

Head (Agens)

$\left[\right.$ Paul $_{\text {Agens }}$ steinigte $_{\text {Instrument }}$ den Käfer $\left.{ }_{\text {Patiens }}\right]$

Instrument

Tail (Patiens)

(Paul stoned the bug)

Figure 2: Instruemtal Concept (cf. Langacker 2002: 217)

The head (agent) of the energy chain initiates the energy to be transmitted to the tail (patient). Figure 1 mirrors a construal in which the instrument through which the energy is passed on is conceptually (and linguistically) omitted. Figure 2 on the other side depicts a concept encompassing all three components (agent-instrument-patient).

Although both structures are basically founded on resultative constructions (cf. Goldberg 1995), the conceptual difference between integrative causal constructions and instrumental construals can be depicted by the following two adapted construction frames:

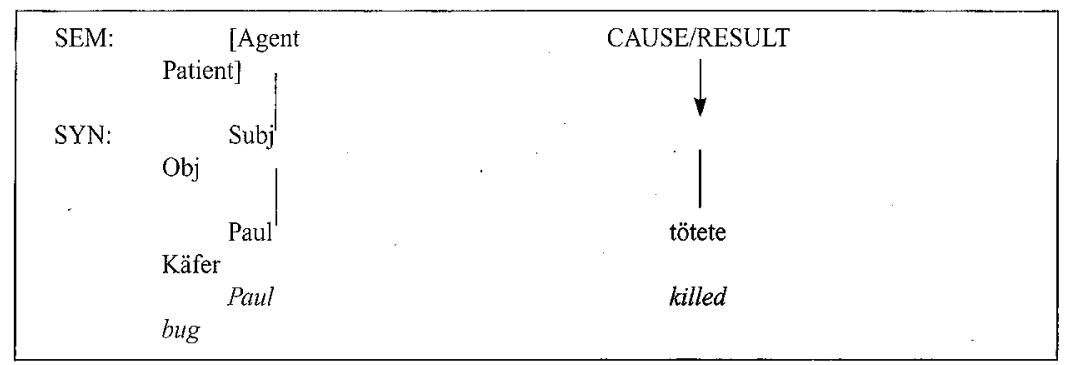

Figure 3: Causative Construction

\begin{tabular}{|c|c|}
\hline SEM: & CAUSE/RESULT/INSTRUMENT \\
SYN: & Patient] \\
& Obj \\
& Käfer Paul \\
bug Paul & stoned \\
\hline
\end{tabular}

Figure 4: Instrumental Construction 
While Figure 3 depicts the conflation of two conceptual moments (cause-result) mapped onto the predicate, Figure 4 demonstrates the integration of yet another aspect, i.e. the instrument.

As examples for single sentences with instrumental verbs compared to plain prototypical causatives consider the following simple sentences:

(1) Paul tötete den Käfer.

(Paul killed the bugl.)

(2) Paul erschlug den Käfer.

(Paul smashed the bug.)

(3) Paul erdolchte den Käfer.

(Paul stabbed the bug.)

(4) Paul steinigte den Käfer.

(Paul stoned the bug.)

Insofar as all these structures integrate cause and effect in the lexical verb (or the affix), they can all be considered as representations of the prototypical or typical causative constructions. Yct, the processes profiled by the verbs in the examples (2) - (4) not only encompass the causal event proper without further specification about the actual happening (as in sentence (1)), but integrate the information about the instrument used (as in (3) and (4)) or at least hint at it (as in (2)).

The profiled situations can be differentiated according to the degree of complexity and informativeness: The lexical causative töten (to kill) directly profiles the causal relation between agent and patient without implying how this relation comes about. In sentence (2) the information about the actual instrument is not verbalized either. Yet, by implying how the action is carried out only a specific range of instruments is possible. That is, the German verb erschlagen (to smash) profiles an action carried out either directly with the agent's hand or with some instrument manipulated by the agent. The verb erschlagen (to smash) thus delimits the notion of possible instruments. The restrictions becomes obvious in the following augmented versions:

(5) Paul crschlug den Käfer mit der Hand/dem Stock.

(Paul smashed the bug with his hand/a stick.)

*Paul erschlug den Käfer mit dem Fuß.

(*Paul smashed the bug with his foot.)

(6) Paul zertrat den Käfer mit dem Fuß.

(Paul crushed the bug with his foot. ${ }^{2}$ )

*Paul zertral den Käfer mit der Hand/einem Stock.

( ${ }^{*}$ Paul crushed the bug with his hand/a stick.)

1 The examples are given in German and English. For some of the examples there is no English equivalent and the closest translation is chosen.

2 Note that the English verb to crush is less specific than the German verb zertreten which always profiles an action carried out with the foot or a shoc. 
In contrast to the verbs töten (lo kill), erschlagen (to smash) or zertreten (to crush) the de-nominalized verbs erdolchen (to stab) or steinigen (to stone) directly display the information about the instrument used.

Since instrumental concepts are sub-concepts of celusative construals the coneptual features which are discernable in causatives have to be discernable in instrumental structures as well. Some of the basic observations about causative constructions will be presented below.

According to Lakoff/Johnson (1980 and 1999) and others (cf. Comrie 1989, Dixon 2000, Shibatani/Pardeshi 2001) causative constructions with lexical causatives such as to kill, to open, to drown etc. are prototypical instantiations of a postulated causal continuum.

In analogy to different conceptual features (Gestalt-qualities) such as temporal and spatial proximity, continuation or bounding single sentences with a lexical causal verb are said to be more prototypical than analytical or complex ${ }^{3}$ sentences in which cause and effect are expressed through two different phrases. On this basis, Comrie (1989) suggested a causal continuum in which the formal aspects of causatives are brought in direct (iconic) correlation with the spatial factors of directness vs. indirectness between cause and result (or agent and patient):

«The distinction between direct and indirect causatives is concerned with the mediacy of the relationship between cause and effect. On the one hand, there are instances where cause and effect are so close to one another temporally that it is difficult to factor the macro-situation physically into cause and effect, even though it remains possible to do so coneeptually. [...] Many languages have a formal distinction correlating with this distinction between direct and indirect causatives. Moreover, the kind of formal distinction found across languages is identical: the continuum from analytical via morphological to lexical causative corrclates with the continum from less to direct to more direct causationy (Comrie 1989: 172).

The causative continuum thus described can be summarized as in the following table:

\begin{tabular}{|c|c|c|c|}
\hline \multicolumn{4}{|c|}{ Conceptual Structure } \\
\hline \multicolumn{2}{|l|}{ direct } & & indirect \\
\hline lexical & morphological & analytical & complex \\
\hline to kill & to over(throw) & complex predicales & subjunctions \\
\hline 10 break & to re(cycle) & prepositions & conjunctions \\
\hline Formal s & & & \\
\hline
\end{tabular}

Table 1: Causative continuum

3 Comrie does not differentiate bctween analytical and complex linguistic structures. Prepositional adjuncts and subordinatcd clauses in complexe sentences depict the relation between cause and rcsult differently and should be considered as mappings of distinct concepts - as well in regard of directness vs. indirectness. 
The gradual differentiation between direct and indirect causation is represented in the following examples:

(7) lexical causative verbs

Poul tötete den Hund.

(Paul killed the dog.)

(8) morphological causatives

Paul warf dic Vase um.

(Paul overthrew the vase.)

(9) analytical causative constructions

prepositional causative constructions

Der Hund starb wegen Paul.

(Owing to Paul the dog died.)

(10) complex causative constructions

Der Hund starb, weil Paut ihn schlug.

(The dog died because Paul hit it.)

In contrast to single sentences, in which causc and effect are merged in one linguistic element (verb), the two constitutive factors of a causal concept can be expressed by two distinct linguistic elements: an affix added to a verb (as in (8)), two separate phrases (as in (9)) or even two autonomous clauses (as in (10)). That is, we have the possibility to conceptualize a causal event not as a causal Gestalt in the first place but to unfold or decompose the coherent whole into their constitutive parts (cause, effect). The representation of the result in the main clause and the cause in the adverbial adjuncts mirrors the conceptual import of the compounds: As sentence topic the patient is conceptually foregrounded or highlighted while the agent or the agent's action is backgtounded.

As indicated above instrumental constructions are a sub-concept of culsative construals and are constructed similarly. Yet, while in causative structures the gradual difference between integrative and complex constructions relates to the decomposition of cause and result, the different instrumental constructions unfold the relation between the causal event as such and the integration of the instrument in this process.

As examples consider the following instantiations:

(11) lexical instrumental verbs

Paul steinigte den Käfer:

(Paul stoned the bug.)

(12) analytical instrumental constructions

prepositional causative constructions

Paul tötete den Käfer mit Steinen.

(Paul killed the bug with stones.)

Paul tötete den Käfer durch das Werfen von Sleinen.

(Paul killed the bug by throwing sloner.) 
(13) complex causative constructions

Paul tötete den Käfer, indem er Steine nach ihm warf.

(Paul killed the bug by throwing stones at it. ${ }^{4}$ )

Paul tötete den Käfer; indem er ihr steinigle.

(Paul killed the bug by stoning it.)

While sentence (11) integrates cause-result-instrument in the verbal form, the other constructions ((12) and (13)) decompose this conflation into the cause-result-relation on one side and the instrumental construal on the other side. With the plain causative construction in the main clause and the instrumental information in the subordinated clause these structures highlight or foreground the causal relation as such and background the instrument or instrumental event.

As far as the spatial factor of dirctness vs. indirectness is concerned the following correlation can be postulated: The relation between the causal event and the involment of the instrument or the instrumental action in this event is represented as the most indirect in sentences (13) and most direct in example (11). Omitting morphological instrumentals which do not exist in German it is thus possible to describe an instrumental continuum based on the conceptual factors dirctness vs. indirectness. In anology to Comrie's causative continuum the description could be as follows:

"A continuum from complex via analytical to lexical instrumcntals correlating with the continuum from less to direct to more direct integration of an instrument in the whole causative event»

\begin{tabular}{|lrr|}
\hline & Conceptual Structure & indirect \\
direct & analytical & complex \\
lexical & prepositions \\
to stone & & subjunctions \\
& Foison & conjunctions
\end{tabular}

Table 2: Instrumental continuum

\section{INTERNAL SETTING-UP}

Yet, the conceptual differentiation between direct $v$ s. indirect causation and instrumental integration is just one aspect among others. The different decomposed concepts mirrored in sentences (12) and (13) differ as well in regard of the accenluation or focusing of the entities involved.

Two factors can be cited to be in force here: a) the perspectival mode towards the scene as a whole and $b$ ) the attentional focus towards the distinct entities involved in the scene.

Reconsider the causative and the instrumental structures from above:

4 Note that the English language does not dispose an instrumental subjunction proper as the German does. 
(1') Paul tötete den Käfer.

(Paul killed the bug.)

(4') Paul steinigte den Käfer.

(Paul stoned the bug.)

(12') Paul tötete den Käfer mit Steinen.

(Paul killed the bug with stones.)

Paul tötete den Käfer durch das Werfen von Steinen.

(Paul killed the bug by throwing stones.)

(13') Paul tötete den Käfer, indern er Steine nach ihm warf.

(Paul killed the bug by throwing stones at it)

Paul tötete den Käfer, indem er ihn steinigte.

(Paul killed the bug by stoning it.)

The integrated structure in $\left(1^{\prime}\right)$ is not only unspecific about the concrete action carried out by the agent (kicking, striking, throwing?) but as well uninformative as far as the instrument used is concerned (a stone, his hand, his foot, poison?). The instantiation in (4') on the other side, implies the information about the instrument used (a stone or stones). At the same time the verb steinigen (to stone) limits the notion of actions carried out by the agent. That is, in general the verb steinigen (to stone) profiles a process in which the agent acts on the instrument and thereby affects the patient, more specifically the process is defined by a concept in which the agent acts on the instrument with his hand and directs the instrument towards the patient - the thus designated process between agent and instrument hardly implies that the agent acted on the stone in the manner of rolling, kicking at it or putting it in front of the patient. The example 4') thus depicts an active process in which a material instrument is integrated in the whole process as a dynamic component and not as a static entity.

Comparing analytical (prepostional) and complex (subordinated) structures with the integrated structures the differentiation between dynamic and static concepts becomes obvious.

The concepts are gradually distinguishable in regard of the representation of the instrument as being either dynamic or static.

(12"a) Paul tötete den Käfer mit Steinen. (Paul killed the bug with stones.)

(b) Paul tötete den Käfer durch das Werfen von Steinen. (Paul killed the bug by throwing stones.)

(13"a) Paul tötete den Käfer, indem er ihn steinigte. (Paul killed the bug by sioning it.)

(b) Paul tötete den Käfer, indem er Steine nach ihm warf. (Paul killed the bug by throwing stones at it)

The prepositional adjunct in sentence (12"a) represents the instruments as static entities. This and the fact that the information about the action performed with the instrument is not vorbalized highlights the instrumental object. 
In (12"b) the adjunctive phrase durch das Werfen von Steinen (by throwing stones) encompasses the action performed on the instrument. Yet, the object complement Werfen defines the action as a static action performed on static entities. The integration of this second conceptual aspect goes hand in hand with an attention shift: As second complement to the object the instrument is backgrounded and the process foregrounded.

The complex sentences presented in (13") have an other conceptual basis. The information about the instrument used to act on the patient is again presented in an adjunctive compound - the subordinated clause. Both adjuncts contain a finite verb which characterizes the conceptualized instrumental event as a dynamic one. However, the instrument as such is integrated quite differently in the two subordinated clauses. In (13"a) the instrument is integrated in the predicate. In this case it is the instrumental event as such that is highlighted and not the material instruments as in (12"a). In (13"b) on the other side the information about instrument and action are decomposed (as in (12"b). The actual course of events is presented as a dynamic action on the static instrument. In contrast to (12"), in which the Agent is not verbalized, these two construals focus first of all on the Agent as initiator of the proceedings. The integrated structure in (13"a) depicts the Patient, (13"b) the Instrument as second focal point.

The comparison between the different constructions thus mirrors our cognitive capacity to conceptualize material quantities as proceedings or vicc versa processes as static entities. It is thus as well possible to verbalize dynamic events as static entities as the following sentences show:
(14) Paul zertrat den Käfer. (Paul kicked the bug)
(15) Paul tötete don Hund mit einem Tritt.
(Paul killed the bug with a kick)
(16) Paul tötete den Hund, indem er ihn trat. (Paul killed the dog by kicking it)

Thus, a perceived event can conceptually either be accelerated or decelerated and a static object can cognitively be transformed into a dynamic event and a dynamic event into a static object.

The different constructions can be explained by the perspcctival mode or the scanning operation involved. As Langacker claims there are two scanning patterns: summary and sequential scaming. The summary scanning is said to be atemporal and collective, with all the patterns/scenes coexistent and simultaneously present. The sequential process on the other side is a successive transformation of one configuration into the next with a positive temporal extension:

«In summary scanning, the various facets of a situation are examined in cumulative fashion, so that progressively a more and more complex conceptualization is built up; once the entire scene has been scanned, all facets of it are simultaneously available and coherc as a single gestalt. [...] By contrast, sequential scanning involves the successive transformation of one scene into another. The various phases of an evolving situation are examined 
scrially, in noncumulative fashion, hence the conceptualization is dynamic, in the sense that its contents change from one instant to the next.s (Langacker 2002: 78/79)

Although Langacker does not subsume the scanning operations under the process of attention or pcrspective there is a close relation between these three schemas. That is, the summary scanning can be considered as holistic view, thus as a perspective in which a viewer has the whole scene or event in perspective; in sequential scanning the scene or event is followed by our «mental eye» and the viewer depicts the entities involved from one instance to the next. This assumption is underlined by Talmy's observation about different perspectival modes:

«Perspectival mode

a) Synoptic mode: the adoption of a stationary distal pcrspective point with global scope of attention

b) Sequential mode: the adoption of a moving proximal perspective point with local scope of attentions?

(lalmy 2000: 70)

Comprised in this is the fact, that in a sequential temporal concept the depicted event is changing continously and can not bc fixed. An atemporal representation on the other side represcnts an atemporal static sequence which can be focused by our «mental eye» over a longer period of time. In other words: As atemporal entity an object is more salient in perception than a temporal event. Thus, in presenting an entity either as noun (stone) or as process (to stone) the conceptual compounds are differently highlighted.

The attentional shift discernable in the different linguistic structures representing instrumental concepts can be summarized as in the following table:

\begin{tabular}{|c|c|c|}
\hline D & Intrumental constructions in German & \\
\hline $\begin{array}{l}\mathrm{N} \\
\mathrm{A}\end{array}$ & $\begin{array}{l}\text { a) Paul tötete den Kăfer mit Steinen. } \\
\text { (Paul killed the bug with stones) }\end{array}$ & $\mathrm{A}$ \\
\hline C & $\begin{array}{l}\text { b) Paul tötete den Kärer durch das Werfen von Stcinen. } \\
\text { (Paul killed the bug by throwing stones) }\end{array}$ & $\begin{array}{l}\mathrm{C} \\
\mathrm{E}\end{array}$ \\
\hline $\begin{array}{l}L \\
I\end{array}$ & $\begin{array}{l}\text { c) Paul tötete den Käfer, inden er Steine warf. } \\
\text { (Paul killed the bug by throwing stones) }\end{array}$ & U \\
\hline $\begin{array}{l}\mathrm{A} \\
\mathrm{T}\end{array}$ & $\begin{array}{l}\text { d) Paul tötete den Käfer, indem cr ihn steinigte. } \\
\text { (Paul killed the bug by stoning it.) }\end{array}$ & $\begin{array}{l}\mathrm{T} \\
\mathrm{I} \\
\mathrm{O}\end{array}$ \\
\hline $\mathrm{O}$ & $\begin{array}{l}\text { e) Paul steinigte den Käfer. } \\
\text { (Paul stoned the bug.) }\end{array}$ & $\mathbb{N}$ \\
\hline
\end{tabular}


To what extend these observations hold for other languages than German can not be answered here and should be subject to further investigations. Yet, as can be seen in instance d) above German and English differ insofar as the English language does not provide an instrumental subjunction.

\section{CONCLUSION}

During the process of conceptualization entities involved in a real-world process or the processes as such can be conceptualized as static or dynamic. These concepts are mapped onto linguistic structures and functions. The basic categorization into static (atemporal) linguistic entities such as nouns or dynamic (temporal) quantities such as verbs and the derivational processes (nominalization vs. denominalization) depiet the distinct conceptual construals. As evidence for this dual construal patterns the range of instrumental constructions represented above can be cited. Our mental ability to construct an instrumental entity, which is usually considered to be a material object, as process (stone à to stone) and vice versa to present a process as concrete instrumental medium (to kick à kick) underlines the gap between real world and conceptual structure. What goes hand in hand with this basic distinction is a shift in conceptual attention.

\section{REFERENCES}

Comrie, Bernaru (1989): Language universals and hnguistic typology. 2. Auflage. Oxrokd: Basil BIACKWFII.

Dixon, R.M.W. (2000): A typology of CausatVes: from, syntax and m Eaning. In: Dixon, R.M.W.' Aikhenvald, Aiexandra Y. (IIrsg.): Changing valency: Case stumits in transitivity. Cam bridge: UnIVERsity Press. $30-83$.

Gombers, Aneje E. (1995): A construchion gramm ar at robach to argum ent structure. Chicago: UniVERSiTY OF ChICAgO Press,

Lakoff, George/Johnson, Maik (1980): Metap hors we hive by. Chicago/London: University of Chicago PRESS.

Lakoni, Gigike/Johnison, Mark (1999): Philosorhy in the flesh: the em bodied mind anj) ris chaLenge TO WESTFRN THOUGHT. NEW YORK: BASIC BOOKS.

Langacker Ronal W. (2002): Concept, im age, and sym bol Thll coginttive basis of gram Mar Berun: DE GRUYTer

Pöp pel, ERnst (1994): Tem poral mechanisus in percertion. Interatanonal Review of Neurobiology 37. $185-202$

Shibatani, Masayushi/ Paferesin, Prashant (2001): The causative continulm, In: Shibatani, Masayoshi: The gram mar of calisaton and INTER ERSONal M anip ULATON. Am STERdam: John Blinaim ins. 85 $-126$.

Taim r, Leonard (2000): Towards a Cognitive Sem antics. Vol 1: Concerit strecturing systems. Cam BRIDGE: MIT PRESS, 